\title{
Whistleblowing System Mempengaruhi Kepatuhan Wajib Pajak Di Indonesia: Apakah Risiko Sanksi Pajak Memoderasi?
}

\author{
Kahfi Fikrianoor ${ }^{\mathrm{a}, 1, *}$, M. Rizki Utama ${ }^{\mathrm{b}, 2}$, Faishal Prahatma Ganinda ${ }^{\mathrm{b}, 3}$, Agung Dwi Nugroho ${ }^{\mathrm{b}, 4}$, \\ Amir Hidayatulloh ${ }^{\mathrm{b}, 5}$ \\ ${ }^{\mathrm{a}, \mathrm{b}}$ Universitas Ahmad Dahlan \\ ${ }^{1}$ kahfifikri@gmail.com *; ${ }^{2}$ rizkiutama572@ gmail.com; ${ }^{3}$ prahatmag@ gmail.com; ${ }^{4}$ agungdwinugroho846@gmail.com; \\ 5 amir.hidayatulloh@act.uad.ac.id \\ * corresponding author
}

\section{ARTICLE INFO}

\section{Keywords}

Whistleblowing System;

Sanction Risk;

Taxpayer Compliance.

\begin{abstract}
The purpose of this research was to determine the effect of whistleblowing system and sanction risk on taxpayer compliance. in addition, this research aims to determine whether the sanctions risk variable moderates between the whistleblowing system to taxpayer compliance in Indonesia. The population in this research is taxpayers in Indonesia. The sample in this research is an individual taxpayer residing in Indonesia. Sampling in this research using convenience sampling. The data collection of this research used a survey method with the help of a questionnaire distributed via Google forms. This research obtained 104 respondents. Data analysis techniques in this research used Partial Least Square with the help of WarpPLS. This research found that tax compliance in Indonesia is influenced by the Whistleblowing system and the risk of tax sanctions. However, the risk of tax sanctions cannot moderate the effect of the whistleblowing system on tax compliance in Indonesia
\end{abstract}

\section{PENDAHULUAN}

Pajak menurut (Undang-undang Nomor 27, 2008) didefinisikan sebagai kontribusi wajib kepada negara yang terutang oleh orang pribadi atau badan yang bersifat memaksa berdasarkan undang-undang, dengan tidak mendapatkan imbalan secara langsung dan digunakan untuk keperluan negara bagi sebesar-besarnya kemakmuran rakyat. Secara umum, pajak merupakan iuran yang diwajibkan oleh negara untuk masyarakat. Berdasarkan undang-undang pajak bersifat dipaksakan dan tergantung oleh yang wajib membayarnya dengan tidak dapat memperoleh timbal balik secara langsung yang hasilnya digunakan untuk membiayai pengeluaran negara dalam menyelenggarakan pembangunan (Siahaan, 2013).

Pajak merupakan pendapatan terbesar yang digunakan untuk APBN, namun jika dilihat dari rasio pajak Indonesia masih tergolong rendah dibandingkan dengan negara lain. Dari data yang dirilis oleh Direktorat Jendral Pajak (DJB) bahwa tax ratio Indonesia setiap tahun menurun. Sebagai contoh dari OECD model tax ratio Indonesia tahun 2016 adalah sebesar 12 persen sedangkan tahun 2017 tax ratio Indonesia sebesar 11,5 persen. Hal tersebut menunjukan bahwa tax ratio Indonesia pada tahun 2017 mengalami penurunan sebesar 0,5 persen. Jika dihitung dari 2007 hingga 2017 tax ratio Indonesia turun sebanyak 0,7 persen dari 12,2 persen menjadi 11,5 persen (Kevin, 2019). Penyebab terjadinya penurunan tax ratio Indonesia adalah rendahnya tingkat kepatuhan wajib pajak dalam membayar pajak, dimana pada sistem pelaporan pajak self assesment system wajib pajak melaporkan sendiri pajak nya sebagaimana untuk memenuhi hak dan kewajiban wajib pajak sesuai dengan undang-undang baik dari segi formil dan material. Pada sistem pelaporan tersebut, wajib pajak dapat melakukan kecurangan atau kejahatan (Siringoringo, 2017).

Data yang dirilis oleh (Kevin, 2019) tentang tax ratio yang dimiliki oleh wajib pajak Indonesia dan dihubungkan dengan penelitian yang dilakukan oleh (Coryanata, 2016) menyatakan bahwa transparansi menjadi hal yang menjadi salah satu faktor untuk mendorong tumbuhnya kepatuhan 
pajak. Oleh karena itu, kepatuhan wajib pajak perlu dtingkatkan dengan adanya tranparansi pengelolaan pajak dalam segala bidang, baik dari administrasi maupun pengelolaan anggaran yang bersumber dari pendapatan pajak tersebut. Transparansi administrasi dan pengelolaan pajak dapat dilakukan dengan menjalankan Whistleblowing system, dimana sistem ini memungkinkan karyawan atau pegawai didalam lingkungan DJB dapat melaporkan apapun yang bersifat kecurangan dalam pajak.

Whistleblowing menurut (Peraturan Menteri Keuangan Nomor 103/PMK.09, 2010) didefinisikan sebagai aplikasi yang disediakan oleh kementrian keuangan bagi pegawai yang memiliki informasi dan ingin melaporkan suatu perbuatan yang mengindikasi kecurangan maupun tindak korupsi dilingkungan yang terjadi di lingkungan kementrian keuangan Indonesia. Penerapan whistleblowing dapat mendorong pengelolaan pajak yang transparan baik dari administrasi maupun pengelolaan anggaran pajak. Hal tersebut untuk memberikan kepercayaan masyarakat terhadap pengelolaan pajak yang dilakukan oleh DJP, hal ini diharapkan bisa meningkatkan kepatuhan wajib pajak. Dari uraian diatas dapat di susun hipotesis kesatu $\left(\mathrm{H}_{1}\right)$ penelitian ini adalah sebagai berikut:

$\mathrm{H}_{1}$ : whistleblowing system berpengaruh terhadap kepatuhan wajib pajak.

Sanksi pajak merupakan pemberian sanksi bagi wajib pajak yang tidak memenuhi kewajiban sesuai dengan peraturan perundang-undang perpajakan yang berlaku. Agar wajib pajak memenuhi kewajibannya maka perlu adanya sanksi bagi pelanggarnya. Wajib pajak akan memenuhi kewajiban nya ketika menganggap bahwa sanksi pajak merugikan bagi individu tersebut (Nugroho \& Masduqi, 2014). Hal ini didukung oleh penelitian (Irmawati \& Hidayatulloh, 2019); (Karnedi \& Hidayatulloh, 2019) yang menyatakan bahwa sanksi pajak berpengaruh terhadap kepatuhan wajib pajak. Dari uraian sebelumnya, maka hipotesis kedua $\left(\mathrm{H}_{2}\right)$ penelitian ini adalah sebagai berikut:

$\mathrm{H}_{2}$ : risiko sanki pajak berpengaruh terhadap kepatuhan wajib pajak.

Menurut (Undang-undang Nomor 13, 2006), ada perlindungan pada saksi dan korban pelapor suatu perkara pidana. Dalam rangka mencegah dan melakukan deteksi awal atas pelanggaran yang mungkin terjadi di lingkungan Direktorat Jenderal Pajak (DJP) melalui peningkatan peran serta pegawai dan masyarakat secara aktif untuk menjadi pelapor pelaporan, DJP menerbitkan Peraturan Direktur Jenderal Pajak Nomor PER-22/PJ/2011.

Sistem pelaporan dan penanganan pelaporan yang tepat di lingkungan Direktorat Jenderal Pajak diharapkan dapat meningkatkan pelaporan pelanggaran. Selain itu, Sistem pelaporan dan penanganan pelaporan yang tepat di lingkungan Direktorat Jenderal Pajak dapat mencegah rasa ingin berbuat curang ataupun melakukan penggelapan pajak. Hal ini karena penegakan hukum juga pasti akan diberikan secara tegas dan baik, sehingga kepatuhan wajib pajak pun semakin meningkat. Pernyataan ini didukung oleh hasil penelitian sebelumnya (Sulistyowatie \& Pahlevi, 2018) yang menyatakan bahwa pengaruh antara penerapan whistleblowing system terhadap kepatuhan pajak dimoderasi oleh variabel risiko sanksi pajak. Dari uraian sebelumnya, maka hipotesis ketiga (H3) penelitian ini adalah sebagai berikut:

$\mathrm{H}_{3}$ : risiko sanksi pajak memoderasi korelasi antara whisteblowing system dengan kepatuhan wajib pajak.

\section{METODE PENELITIAN}

Penelitian ini merupakan penelitian kuantitatif. Populasi dalam penelitian ini adalah wajib pajak Indonesia dan sampel penelitian ini adalah wajib pajak orang pribadi yang ada di Indonesia. Pengambilan sampel dalam penelitian ini menggunakan convenience sampling. Pengumpulan Data penelitian ini menggunakan metode survei dengan bantuan kuesioner yang disebarkan melalui google form. Teknik analisis data dalam penelitian ini menggunakan Partial Least Square dengan bantuan WarpPLS. Variabel penelitian ini terdiri dari Whistleblowing, risiko sanksi pajak dan kepatuhan wajib pajak.

Definisi operasional dan pengukuran variabel dalam penelitian ini disajikan kedalam tabel 1. 
Tabel 1. Definisi Operasional dan Pengukuran Variabel

\begin{tabular}{|c|c|c|c|c|}
\hline keterangan & Definisi Operasional & Referensi & Pengukuran & Referensi \\
\hline $\begin{array}{l}\text { Kepatuhan } \\
\text { pajak }\end{array}$ & $\begin{array}{l}\text { Pemenuhan kewajiban } \\
\text { perpajakan yang } \\
\text { dilakukan oleh pembayar } \\
\text { pajak dalam rangka } \\
\text { memberikan kontribusi } \\
\text { bagi pembangunan } \\
\text { negara sehingga wajib } \\
\text { pajak dapat memenuhi } \\
\text { kewajiban perpajakannya } \\
\text { secara sukarela. }\end{array}$ & $\begin{array}{l}\text { (Tiraada, } \\
\text { 2013) }\end{array}$ & $\begin{array}{l}\text { Tujuh pertanyaan } \\
\text { item pertanyaan } \\
\text { yang diukur dengan } \\
\text { menggunakan lima } \\
\text { skala likert poin }\end{array}$ & $\begin{array}{l}\text { (Sulistyowatie } \\
\& \quad \text { Pahlevi, } \\
\text { 2018) }\end{array}$ \\
\hline Risiko sanksi & $\begin{array}{l}\text { Pemberian sanksi bagi } \\
\text { wajib pajak yang tidak } \\
\text { memenuhi kewajiban } \\
\text { sesuai dengan peraturan } \\
\text { perundang-undang } \\
\text { perpajakan yang berlaku. } \\
\text { Agar wajib pajak } \\
\text { memenuhi kewajibannya } \\
\text { maka perlu adanya sanksi } \\
\text { bagi pelanggarnya }\end{array}$ & $\begin{array}{l}\text { (Nugroho \& } \\
\text { Masduqi, } \\
\text { 2014) }\end{array}$ & $\begin{array}{l}\text { Tujuh pertanyaan } \\
\text { item pertanyaan } \\
\text { yang diukur dengan } \\
\text { menggunakan lima } \\
\text { skala likert poin }\end{array}$ & $\begin{array}{l}\text { (Sulistyowatie } \\
\& \quad \text { Pahlevi, } \\
\text { 2018) }\end{array}$ \\
\hline $\begin{array}{l}\text { Whistle } \\
\text { blowing }\end{array}$ & $\begin{array}{l}\text { Aplikasi yang disediakan } \\
\text { oleh kementrian } \\
\text { keuangan bagi pegawai } \\
\text { yang memiliki informasi } \\
\text { dan ingin melaporkan } \\
\text { suatu perbuatan yang } \\
\text { mengindikasi kecurangan } \\
\text { dilingkungan yang terjadi } \\
\text { di lingkungan kementrian } \\
\text { keuangan Indonesia }\end{array}$ & $\begin{array}{l}\text { (Peraturan } \\
\text { Menteri } \\
\text { Keuangan } \\
\text { Nomor } \\
\text { 103/PMK.9, } \\
\text { 2010) }\end{array}$ & $\begin{array}{l}\text { Sembilan } \\
\text { pertanyaan item } \\
\text { pertanyaan yang } \\
\text { diukur dengan } \\
\text { menggunakan lima } \\
\text { skala likert poin }\end{array}$ & $\begin{array}{l}\text { (Sulistyowatie } \\
\& \quad \text { Pahlevi, } \\
\text { 2018) }\end{array}$ \\
\hline
\end{tabular}

Dalam pengujian hipotesis, peneliti terlebih dahulu melakukan pilot study. Pilot study merupakan pengkajian kembali pernyataan yang berada pada kuesioner agar dapat dipahami dengan mudah oleh responden yang akan mengisi kuesioner. Analisis data dalam penelitian ini menggunakan WarpPLS. WarpPLS merupakan sebagai alat untuk melakukan persamaan struktural (SEM) berbasis varian yang secara simultan dapat melakukan pengujian model pengukuran dan pengujian model struktural (Nugroho \& Masduqi, 2014)

\section{HASIL dan PEMBAHASAN}

Deskripsi responden dalam penelitian ini meliputi jenis kelamin, jenjang pendidikan, usia, dan domisili KPP. Jumlah responden dalam penelitian 104 orang terdiri dari 59 orang laki-laki dan 45 orang perempuan, rentan usia dari responden ini terdiri dari 37 orang berusia 20-25 tahun, 17 orang berusia 26-30 tahun, 13 orang berusia 31-35 tahun, 10 orang berusia antara 36-40 tahun, 7 orang berusia antara 41-45 tahun, 12 orang berusia antara 46-50 tahun, 4 orang berusia antara 5155 tahun, 3 orang berusia antara 56-60 tahun, dan 1 orang berusia antara 61-65 tahun. Tingkat pendidikan responden dalam penelitian ini terdiri dari 15 orang berpendidikan SMA, 14 orang berpendidikan Diploma, 74 orang berpendidikan S1, dan 1 orang berpendidikan S2. Adapun domisili KPP responden di sajikan kedalam tabel 2. 
Tabel 2. Domisli KPP

\begin{tabular}{|l|c|l|c|}
\hline \multicolumn{1}{|c|}{ Domisili KPP } & $\begin{array}{c}\text { Jumlah } \\
\text { responden }\end{array}$ & \multicolumn{1}{|c|}{ Domisili KPP } & $\begin{array}{c}\text { Jumlah } \\
\text { Responden }\end{array}$ \\
\hline Jambi & 1 & Jawa Barat & 4 \\
\hline Riau & 2 & Jawa tengah & 5 \\
\hline Sumatra selatan & 1 & Jawa Timur & 9 \\
\hline Bangka Belitung & 1 & DIY & 17 \\
\hline Lampung & 2 & Kalimantan Barat & 2 \\
\hline Banten & 2 & Kalimantan Tengah & 2 \\
\hline DKI Jakarta & 8 & Kalimantan Selatan & 5 \\
\hline Gorontalo & 1 & Maluku Utara & 2 \\
\hline Bali & 3 & NTB & 23 \\
\hline NTT & 2 & Papua & 1 \\
\hline Papua Barat & 3 & Sulawesi Selatan & 8 \\
\hline
\end{tabular}

Sumber: data primer, diolah (2019)

Dari tabel 2 dapat diketahui bahwa responden dari penelitian ini terdiri dari responden yang berasal dari 22 provinsi. Dominasi responden berasal dari provinsi Nusa Tenggara Barat (NTB) dan Provinsi Daerah Istimewa Yogyakarta (DIY) yaitu sebanyak 23 responden dan 17 responden.

Penelitian ini melakukan model pengukuran, dengan tujuan untuk menguji validitas konstruk dan reliabilitas instrumen (Jogiyanto \& Abdillah, 2014). Uji validitas yang dilakukan dalam penelitian ini adalah validitas konstruk. Validitas konstruk meliputi validitas konvergen dan validitas diskriminan. Validitas konvergen berhubungan dengan prinsip pengukur dari konstruk seharusnya tinggi. Sedangkan, validitas diskriminan berhubungan bahwa pengukur konstruk yang berbeda seharusnya tidak berkorelasi tinggi (Jogiyanto \& Abdillah, 2014). Hasil uji validitas disajikan pada tabel 3 .

Tabel 3. Hasil Uji Validitas

\begin{tabular}{|c|c|c|c|c|}
\hline & Whistleblowing & Kepatuhan Wajib Pajak & Risiko Sanksi Pajak & AVE \\
\hline W1 & 0,725 & & & \multirow{7}{*}{0,807} \\
\hline W2 & 0,745 & & & \\
\hline W3 & 0,855 & & & \\
\hline W4 & 0,726 & & & \\
\hline W5 & 0,808 & & & \\
\hline W6 & 0,782 & & & \\
\hline W7 & 0,784 & & & \\
\hline KWP1 & & 0,844 & & \multirow{8}{*}{0,861} \\
\hline KWP2 & & 0,875 & & \\
\hline KWP3 & & 0,882 & & \\
\hline KWP4 & & 0,881 & & \\
\hline KWP5 & & 0,805 & & \\
\hline KWP6 & & 0,768 & & \\
\hline KWP7 & & 0,818 & & \\
\hline RS1 & & & & \\
\hline RS2 & & & 0,709 & \multirow{8}{*}{0,865} \\
\hline RS3 & & & 0,882 & \\
\hline RS4 & & & 0,899 & \\
\hline RS5 & & & 0,914 & \\
\hline RS6 & & & 0,902 & \\
\hline RS7 & & & 0,816 & \\
\hline RS8 & & & 0,896 & \\
\hline RS9 & & & 0,811 & \\
\hline
\end{tabular}

Sumber: data primer, diolah (2019)

Tabel 3 menunjukan bahwa semua item pernyataan kuesioner valid. Hal ini dapat dilihat dari nilai loading yang lebih besar dari 0,7 dan nilai AVE lebih besar dari 0,5. Uji reliabilitas bertujuan untuk mengukur konsistensi internal alat ukur. Parameter yang digunakan untuk uji reliabilitas ini yaitu, composite reliability dengan nilai rule of thumb lebih besar dari 0,7 (Sholihin, 2013). 
Tabel 4. Hasil Uji Realibilitas

\begin{tabular}{|c|c|c|c|}
\hline \multirow{2}{*}{ Nilai Composite Reability } & Whistleblowing & $\begin{array}{c}\text { Kepatuhan Wajib } \\
\text { Pajak }\end{array}$ & $\begin{array}{c}\text { Risiko } \\
\text { Sanski pajak }\end{array}$ \\
\cline { 2 - 4 } & 0,937 & 0,958 & 0,967 \\
\hline
\end{tabular}

Sumber: data primer, diolah (2019)

Tabel 4 menunjukan hasil uji reabilitas dengan menggunakan metode composite reability dengan nilai rule of thumb lebih besar dari 0,7 . Oleh karena itu, penelitian ini memenuhi uji reliabilitas.

Tahap selanjutnya setelah pengujian model pengukuran adalah pengujian model struktural. Pengujian struktural dilakukan dengan menggunakan $R$-Square dan nilai koefisien path atau $t$-value tiap path. Hasil model stuktural disajikan pada gambar 1 .

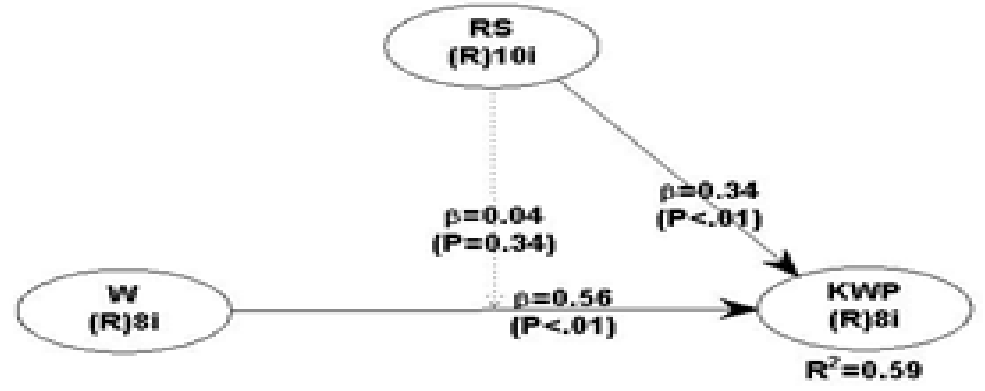

Gambar 1. Hasil Outer model

Sumber: data primer, diolah (2020)

Gambar 1 menunjukan bahwa R-Square adalah sebesar 0,59 atau sebesar 59 persen. Hal ini berarti bahwa kepatuhan wajib pajak dapat dijelaskan oleh whistleblowing system dan risiko sanksi pajak sebesar 59 persen. Sedangkan 41 persen dapat dijelaskan oleh variabel diluar model penelitian.

Gambar 1 menunjukan bahwa whistleblowing berpengaruh terhadap kepatuhan wajib pajak. Hal tersebut dapat diliat dari nilai signifikansi yaitu $(<0,01)$ yang lebih kecil dari 0,05 . Dengan kata lain hipotesis pertama $\left(\mathrm{H}_{1}\right)$ dari penelitian ini terdukung. Penerapan whistleblowing dapat mendorong pengelolaan pajak yang transparan baik dari administrasi maupun pengelolaan anggaran pajak. Hal tersebut untuk memberikan kepercayaan masyarakat terhadap pengelolaan pajak yang dilakukan oleh DJP, hal ini diharapkan bisa meningkatkan kepatuhan wajib pajak. Hasil ini didukung oleh penelitian yang dilakukan oleh (Aryati \& Putritanti, 2017) yang menyatakan bahwa whistleblowing system berpengaruh terhadap kepatuhan wajib pajak.

Risiko sanksi pajak bepengaruh terhadap kepatuhan wajib pajak. Hal tersebut dapat dilihat dari outer model bahwa nilai signifikansi yaitu $(<0,01)$ lebih kecil dari 0,05 dengan nilai koefesiensi sebesar 0,34. Oleh karena itu, hipotesis kedua $(\mathrm{H} 2)$ dari penelitian ini terdukung. Sehingga, risiko sanksi pajak berpengaruh terhadap kepatuhan wajib pajak. Sanksi pajak merupakan pemberian sanksi bagi wajib pajak yang tidak memenuhi kewajiban sesuai dengan peraturan perundang-undang perpajakan yang berlaku. Hal ini bertujuan agar wajib pajak memnuhi kewajiban perpajakannya. Hasil penelitian ini didukung oleh penelitian yang dilakukan oleh (Sulistyowatie \& Pahlevi, 2018); (Irmawati \& Hidayatulloh, 2019); (Karnedi \& Hidayatulloh, 2019) yang menyatakan bahwa risiko sanksi pajak berpengaruh terhadap kepatuhan wajib pajak.

Gambar 1 juga menunjukan bahwa risiko sanksi pajak tidak memoderasi antara Whistleblowing sytem terhadap kepatuhan wajib pajak. hal tesebut dapat dilihat bahwa nilai signifikansi yaitu 0,34 dimana tingkat signifikan tersebut lebih besar dari 0,05 yang berati hipotesis ketiga $\left(\mathrm{H}_{3}\right)$ penelitian ini tidak terdukung. Hal ini disebabkan karena risiko sanksi pajak kemungkinan merupakan variabel independen. Pernyataan ini didukung oleh hasil penelitian (Irmawati \& Hidayatulloh, 2019); (Karnedi \& Hidayatulloh, 2019). 


\section{KESIMPULAN}

Penelitian ini memperoleh hasil bahwa kepatuhan wajib pajak di Indonesia dipengaruhi oleh whistleblowing system dan risiko sanksi pajak. Wajib pajak akan menghindari adanya sanksi pajak, karena wajib pajak akan merasa bahwa sanksi pajak cukup merugikan bagi mereka yang melanggar peraturan dalam perpajakan. Selain risiko sanksi pajak, dengan adanya whistleblowing maka pegawai atau karyawan pajak akan berhati-hati dalam menjalankan tugas pelayanan publik. Whistleblowing dapat menjadi alat pengendali didalam lingkungan pengelolaan pajak sehingga menyebabkan kepercayaan, kepatuhan dan kepuasan wajib pajak meningkat. Akan tetapi risiko sanksi pajak tidak dapat memoderasi pengaruh whistleblowing system terhadap kepatuhan pajak di Indonesia. Hal tersebut disebabkan karena risiko sanksi pajak merupakan variabel independen.

Penelitian ini memiliki keterbatasan yaitu responden penelitian berasal dari 22 propinsi, namun penyebaran responden belum merata. Sehingga, penelitian selanjutnya dapat menggunakan sampel seluruh Indonesia dengan rata-rata responden tiap propinsinya merata.

\section{DAFTAR PUSTAKA}

[1]. Aryati, T., \& Putritanti, L. R. (2017). Pengaruh Pemanfaatan Teknologi Dan Modernisasi Sistem Administrasi Perpajakan Terhadap Kepatuhan Wajib Pajak Orang Pribadi. Jurnal Riset Akuntansi Dan Keuangan, 4(3), 1155-1168. https://doi.org/10.17509/jrak.v4i3.4669

[2]. Coryanata, I. (2016). Akuntabilitas, Partisipasi Masyarakat Dan Transparansi Kebijakan Publik Sebagai Pemoderasi Hubungan Pengetahuan Dewan Tentang Anggaran Dan Pengawasan Keuangan Daerah. Journal of Accounting and Investment, 12(2), 110-125. Retrieved from http://journal.umy.ac.id/index.php/ai/article/view/678

[3]. Irmawati, J., \& Hidayatulloh, A. (2019). Determinan Kepatuhan Wajib Pajak Umkm Di Kota Yogyakarta. Jurnal SIKAP (Sistem Informasi, Keuangan, Auditing Dan Perpajakan), 3(2), 112. https://doi.org/10.32897/jsikap.v3i2.118

[4]. Jogiyanto, H., \& Abdillah, W. (2014). Konsep dan Aplikasi (Partial Least Square) untuk Penelitian Empiris. Yogyakarta, Indonesia: BPFE UGM, Edisi 1.

[5]. Karnedi, N. F., \& Hidayatulloh, A. (2019). Pengaruh Kesadaran Perpajakan, Sanksi Pajak dan Tax Amnesty Terhadap Kepatuhan Wajib Pajak Orang Pribadi. 12(1), 1-9. https://doi.org/10.22441/profita.2019.v12.01.001

[6]. Kevin, A. (2019). miris-ternyata-tax-ratio-indonesia-terendah-di-asia-pasifik. Retrieved January 9, 2020, from https://www.cnbcindonesia.com/news/20190726094730-4-87743/miris-ternyata-tax-ratioindonesia-terendah-di-asia-pasifik

[7]. Nugroho, A. R., \& Masduqi, A. (2014). Application of Partial Least Square Structural Equation Modelling for Assessing the Water Pollution Factor of Kali Aplikasi Partial Least Square Structural Equation Modelling Untuk Menilai Faktor Pencemaran Air Application of Partial Least Square Structur. (April 2018).

[8]. Peraturan Menteri Keuangan Nomor 103/PMK.9, P. N. (2010). Tata Cara Pengelolaan Dan Tindak Lanjut Pelaporan Pelanggaran (Whistleblowing) Di Lingkungan Kementerian Keuangan.

[9]. Sholihin, M. (2013). Analisis SEM-PLS dengan WarpPLS 3.O. Yogyakarta: Andi Offset.

[10]. Siahaan, P. M. (2013). Pajak Daerah dan Retribusi Daerah Berdasarkan Undang-Undang Nomor 28 Tahun 2009 Tentang Pajak Daerah dan Retribusi Daerah. Rajawali Press.

[11]. Siringoringo, W. (2017). Pengaruh Penerapan Good Governance Dan Whistleblowing System Terhadap Kepatuhan Wajib Pajak Orang Pribadi Dengan Resiko Sanksi Pajak Sebagai Variabel Moderating (Studi Empiris Terhadap Wajib Pajak Orang Pribadi Di Kota Bekasi). Jurnal Akuntansi, 19(2), 207. https://doi.org/10.24912/ja.v19i2.95

[12]. Sulistyowatie, S. L., \& Pahlevi, R. W. (2018). Penerapan Good Corporate Governance, Whistleblowing System Dan Risiko Sanksi Pajak Terhadap Kepatuhan Wajib Pajak Di Kabupaten Sleman. Riset Akuntansi Dan Keuangan Indonesia, 3(2), 152-160. https://doi.org/10.23917/reaksi.v3i2.6743

[13]. Tiraada, T. (2013). Kesadaran Perpajakan,Sanksi Pajak,Sikap Fiskus Terhadap Kepatuhan WPOP Di Kabupaten Minahasa Selatan. Emba, 1(3), 999-1008. https://doi.org/10.1017/CBO9781107415324.004

[14]. Undang-Undang Nomor 13 Tahun 2006 Tentang Perlindungan Sanksi dan Korban.

[15]. Undang-Undang Nomor 27 Tahun 2008 Tentang Ketentuan Umum dan Tata Cara Perpajakan. 